Disclosure of Interest: None declared

DOI: 10.1136/annrheumdis-2017-eular.1132

\section{AB0434 TOFACITINIB IN RHEUMATOID ARTHRITIS: REAL LIFE EXPERIENCE}

P. Sansinanea ${ }^{1}$, A.C. Costi ${ }^{1}$, A. Vulcano ${ }^{2}$, A.P. Salas ${ }^{2}$, J. Marcos ${ }^{3}$, M.A. Belini ${ }^{4}$, M.A. García ${ }^{2}{ }^{1}$ Rheumatology Unit, Sanatorio Ipensa, HIGA San Martín la Plata; ${ }^{2}$ Rheumatology Unit, HIGA San Martín la Plata; ${ }^{3}$ Rheumatology Unit, Sanatorio IPENSA, Pfizer Inc., la Plata: ${ }^{4}$ Medical Affairs, Pfizer Inc, CABA, Argentina

Background: Tofacitinib is a new small molecule, Janus kinase 1 and 3 inhibitor, interfering with the JAK-STAT signaling pathway. The JAK-STAT transmits the extracellular information in the cell nucleus, influencing DNA transcription. Its efficacy and safety in Rheumatoid Arthritis (RA) has been demonstrated in different phase II, III and long-term clinical studies. It has been approved in Argentina for the treatment of patients with moderate to severe rheumatoid arthritis RA with failure to conventional DMARDs.

Objectives: To communicate real world safety data from patients with RA under treatment with Tofacitinib.

Methods: A retrospective, descriptive study from patients with RA (ACR/ EULAR2010) under treatment with Tofacitinib from September 2014 to December 2016 was conducted. Medical records from patients being treated with Tofacitinib were reviewed and demographic data were recorded. Comorbidities, concomitant treatments, and reported adverse effects were documented.

Results: 62 patients were treated with Tofacitinib. 53 were female and 9 were male, with a mean age of $57.91 \pm 14.72$ years and average disease duration of $140.09 \pm 130.83$ months. 18 patients $(29 \%)$ had at least one comorbidity, the most frequent being hypertension $(77 \%)$.

Of the 62 patients studied, $54(87 \%)$ had established RA (duration of illness greater than 24 months) and 8 patients (13\%) with early RA (less than 24 months). In 54 patients Tofacitinib was indicated in combination with another DMARD $(87 \%)$, and only 6 patients received treatment as monotherapy.

The most commonly used DMARD in combination therapy was methotrexate (MTX) in $92.5 \%$

Treatments were indicated by failure to MTX or other conventional DMARDs, $12 / 62$ treatments were indicated by failure to treatment with 1 biological DMARD and 13/62 treatments were indicated by failure to two or more biological DMARDs. The maximum exposure time was 21 months.

During the time of exposure to Tofacitinib the following adverse events were observed: Herpes Zoster infection 2 cases (monometameric, no visceral involvement in unvaccinated patients), upper airway infection 1 case, transient increase in liver enzymes 1 case, peripheral facial paralysis 1 case, tachycardia 1 case. There were no cases of serious infections, opportunistic infections, cytopenias, dyslipidemia, or increased CPK.

Three patients discontinued Tofacitinib: one due to tachycardia, another case peripheral facial paralysis and another case due inefficacy.

Conclusions: Most patients received combined treatment with DMARDs being the most commonly used Methotrexate. There were no cases of serious infections, opportunistic infections, cytopenias or dyslipidemia. The use of Tofacitinib in RA patients in our cohort showed a comparable safety profile with long-term extension studies in the treatment of patients with RA diagnosed with failure of conventional or biological DMARDs.

Disclosure of Interest: None declared

DOI: 10.1136/annrheumdis-2017-eular.3861

\section{AB0435 COMBINATION THERAPY IN EARLY STAGE OF RHEUMATOID ARTHRITIS}

S.X. Matchanov. Internal disease, Tashkent Medical Academy, Tashkent, Uzbekistan

Background: It is known that the early period of rheumatoid arthritis (RA) has a critical role in the development and progression of immune inflammation. Allocation of early RA is due to the need for timely appointment of basic anti-inflammatory drugs to prevent the development of destructive changes in the joints and improve its current forecast. We have proposed a combination of two basic drugs for the treatment of RA, methotrexate (MTX) and leflunomide (LF). While this combination, we proceeded from the basic principles of combination therapy: each of the drugs has an independent clinical effect in early RA, the drugs have different mechanisms of action and different spectrum of side effects. Objectives: Investigating of clinical efficacy of combination therapy with MT and LF in patients with RA in its early stages

Methods: We observed 80 patients with early RA, 50 patients of them were women and 30 patients were male. The age of patients ranged from 24 up to 42 years old $(31,7 \pm 7,6)$, the duration of illness was 6 months. Activity of RA was corresponded to the II degree (DAS $28<4.7$ ) in 48 patients, III degree (DAS28 $>5,1$ ) was in 32 patients. 1st group consisted of 40 patients and the 2 nd group involved 40 patients. Patients in 1 st group received combination therapy with LF in doses $20 \mathrm{mg} /$ day and MT in doses $7.5 \mathrm{mg} /$ week. 2nd group received just MT as a single basic anti-inflammatory drug in doses $7.5 \mathrm{mg} /$ week. In order to improve portability of MT was administered to all patients folic acid in doses 1.2 $\mathrm{mg} /$ day, 5 days in a week. The efficiency of the intervention was evaluated after 6 months by reducing of the final value of the indicator of inflammatory activity. Results: The results of observation of patients for 6 months were showed that, combination therapy with MT and LF provides a quick and pronounced clinical effect in patients in the early stages of RA. Patients of 1st group according to criteria ACR $50-70 \%$ improvement was achieved in $50 \%$ of patients, while figure of all indicators of patients in 2 nd group was $33.4 \%$. During the treatment was indicated improvement of laboratory parameters of disease activity of RA in both groups, features of activity of 1 st group were decreased up to (DAS28 $=2,9$ ), signs of 2 nd group were (DAS28 $=3,6$ ). However, there were $26 \%$ of cases of clinical remission of the disease in patients of 1 st group than patients of 2 nd group. Known side effects of combination therapy with MT and LF in most cases have not been severe, reversible and demanded the abolition of drugs in rare (11.2\%) cases. Conclusions: Combined basic therapy of patients in the early stages of RA with LF and MT has more efficiency than mono therapy.

Disclosure of Interest: None declared

DOI: 10.1136/annrheumdis-2017-eular.4770

\section{AB0436 COMPARISON OF TOFACITINIB EFFICACY IN PATIENTS WITH MODERATE VS SEVERE RHEUMATOID ARTHRITIS: POOLED ANALYSIS OF PHASE 3 STUDIES}

S. Schwartzman ${ }^{1}$, P. Sunkureddi ${ }^{2}$, L. Takiya ${ }^{3}$, M. Snyder ${ }^{3}$, H. Fan ${ }^{4}$, T. Lukic ${ }^{5}$, J. Roberts ${ }^{6}$, W.F.C. Rigby ${ }^{7} .{ }^{1}$ Hospital for Special Surgery, New York, NY; ${ }^{2}$ Clear Lake Rheumatology, Nassau Bay, TX; ${ }^{3}$ Pfizer Inc, Collegeville, PA; ${ }^{4}$ Pfizer Inc, Groton, CT; ${ }^{5}$ Pfizer Inc, New York, NY, United States; ${ }^{6}$ Pfizer Inc, Tadworth, United Kingdom; ${ }^{7}$ Geisel School of Medicine at Dartmouth, Lebanon, NH, United States

Background: Tofacitinib is an oral JAK inhibitor for the treatment of RA.

Objectives: To evaluate tofacitinib 5 and $10 \mathrm{mg}$ twice daily (BID) efficacy in patients (pts) with moderate vs severe RA.

Methods: Tofacitinib 5 and $10 \mathrm{mg}$ BID efficacy data were obtained from 6 randomised double-blind Phase 3 studies of 6-24 months' duration. Tofacitinib was administered as monotherapy (NCT00814307 ORAL Solo; NCT01039688 ORAL Start) or with csDMARDs, mainly MTX (NCT00960440 ORAL Step; NCT00847613 ORAL Scan; NCT00856544 ORAL Sync; NCT00853385 ORAL Standard). Pts receiving MTX monotherapy (ORAL Start), or placebo ( \pm csDMARDs) were combined as a single "placebo" group. Baseline (BL) disease severity was classified as moderate or severe using Disease Activity Score in 28 joints with erythrocyte sedimentation rate (DAS28: moderate 3.2 to $\leq 5.1$; severe $>5.1$ ) and Clinical Disease Activity Index (CDAl: moderate 10 to $\leq 22$; severe $>22$ ). Month 3 (M3) efficacy outcomes included: pts (\%) achieving low disease activity (LDA; DAS28 $\leq 3.2$, CDAl $\leq 10$ ), remission (DAS28 $<2.6$, CDAl $\leq 2.8$ ), HAQ-DI $<0.5$ (normal physical functioning), HAQ-DI improvement $>0.22$ and mean change from BL $(\Delta)$ in DAS28, CDAI and HAQ-DI. This post hoc analysis had no multiplicity adjustments.

Results: Overall, more pts had severe BL disease by DAS28 (91.0\%) and CDAI $(89.5 \%)$. The table shows BL disease characteristics and M3 efficacy outcomes for pts classified by BL DAS28 disease severity; CDAI classification demonstrated similar trends.

Table. Baseline disease characteristics (A) and Month 3 efficacy outcomes $(B)$ by baseline disease severity assessment using DAS28

A) Mean (SD) baseline demographics and characteristics

\begin{tabular}{|c|c|c|c|c|c|c|}
\hline \multirow{2}{*}{$\begin{array}{l}\text { Baseline disease severity } \\
\text { Treatment group }\end{array}$} & \multicolumn{3}{|c|}{ Moderate ( 3.2 to $\leq 5.1)$} & \multicolumn{3}{|c|}{ Severe $(>5.1)$} \\
\hline & $\begin{array}{c}\text { Tofacitinib } \\
5 \text { mg BID } \\
\mathrm{N}=120\end{array}$ & $\begin{array}{c}\text { Tofacitinib } \\
10 \mathrm{mg} \mathrm{BID} \\
\mathrm{N}=127\end{array}$ & $\begin{array}{c}\text { Placebo } \\
\mathrm{N}=76\end{array}$ & $\begin{array}{c}\text { Tofacitinib } \\
5 \text { mg BID } \\
\text { N=1427 }\end{array}$ & $\begin{array}{c}\text { Tofacitinib } \\
10 \mathrm{mg} \mathrm{BID} \\
\mathrm{N}=1438\end{array}$ & $\begin{array}{l}\text { Placebo } \\
\mathrm{N}=766\end{array}$ \\
\hline Disease duration, years & $7.1(7.6)$ & $7.7(9.2)$ & $8.7(8.1)$ & $7.4(7.9)$ & $7.7(8.0)$ & $7.7(8.3)$ \\
\hline CDAI & $20.7(6.2)$ & $19.5(5.4)$ & $20.3(6.9)$ & $39.4(11.7)$ & $39.1(11.8)$ & $39.3(12.1)$ \\
\hline DAS28 & $4.6(0.5)$ & $4.7(0.4)$ & $4.7(0.4)$ & $6.7(0.8)$ & $6.6(0.8)$ & $6.6(0.9)$ \\
\hline HAQ-DI & $1.0(0.7)$ & $0.8(0.7)$ & $0.9(0.7)$ & $1.5(0.6)$ & $1.5(0.6)$ & $1.5(0.6)$ \\
\hline \multicolumn{7}{|l|}{ B) Month 3 efficacy outcomes } \\
\hline $\begin{array}{l}\text { Remission (DAS28<2.6), } \\
\% \text { (CI) }\end{array}$ & $\begin{array}{c}20.0 * * \\
(14.9,31.5)\end{array}$ & $\begin{array}{c}22.8^{* *} \\
(18.3,35.3)\end{array}$ & $\begin{array}{c}5.3 \\
(1.7,14.6)\end{array}$ & $\begin{array}{c}6.2^{* z=} \\
(5.6,8.5)\end{array}$ & $\begin{array}{c}9.0^{* * * *} \\
(8.5,11.9)\end{array}$ & $\begin{array}{c}2.0 \\
(1.2,3.5)\end{array}$ \\
\hline $\begin{array}{l}\text { LDA (DAS28 } \leq 3.2) \text {, } \\
\% \text { (CI) }\end{array}$ & $\begin{array}{c}36.7 * * * \\
(31.7,51.1)\end{array}$ & $\begin{array}{c}32.3^{* * *} \\
(28.0,46.6)\end{array}$ & $\begin{array}{c}9.2 \\
(4.3,20.4)\end{array}$ & $\begin{array}{c}13.8^{* * *} \\
(13.6,17.6)\end{array}$ & $\begin{array}{c}19.1^{* * *} \\
(19.1,23.6)\end{array}$ & $\begin{array}{c}4.6 \\
(3.5,6.9)\end{array}$ \\
\hline $\begin{array}{l}\text { HAQ-DI }<0.5 \text {, } \\
\% \text { (CD) }\end{array}$ & $\begin{array}{c}45.0 \\
(35.9,54.4)\end{array}$ & $\begin{array}{c}60.6^{* * *} \\
(51.6,69.2)\end{array}$ & $\begin{array}{c}32.9 \\
(22.5,44.6)\end{array}$ & $\begin{array}{c}24.5^{* * *} \\
(22.6,27.2)\end{array}$ & $\begin{array}{c}30.0^{* * *} \\
(28.0,32.8)\end{array}$ & $\begin{array}{c}12.8 \\
(10.6,15.5)\end{array}$ \\
\hline $\begin{array}{l}\text { HAQ-DI improvement } \\
>0.22, \% \text { (CI) }\end{array}$ & $\begin{array}{c}50.8^{*} \\
(41.6,60.1)\end{array}$ & $\begin{array}{c}55.9^{* *} \\
(46.8,64.7)\end{array}$ & $\begin{array}{c}31.6 \\
(21.7,43.8)\end{array}$ & $\begin{array}{c}66.2^{* * *} \\
(64.8,69.8)\end{array}$ & $\begin{array}{c}72.4^{* * * *} \\
(71.0,75.7)\end{array}$ & $\begin{array}{c}50.7 \\
(47.6,54.8)\end{array}$ \\
\hline$\triangle \mathrm{DAS} 28, \mathrm{LS}$ mean $(\mathrm{CI})$ & $\begin{array}{c}-1.1^{* * *} \\
(-1.4,-0.9)\end{array}$ & $\begin{array}{c}-1.3^{* * *} \\
(-1.6,-1.1)\end{array}$ & $\begin{array}{c}-0.1 \\
(-0.3,0.2)\end{array}$ & $\begin{array}{c}-2.0 * * * \\
(-2.1,-2.0)\end{array}$ & $\begin{array}{c}-2.3 * * * \\
(-2.3,-2.2)\end{array}$ & $\begin{array}{c}-1.1 \\
(-1.2,-1.0)\end{array}$ \\
\hline $\begin{array}{l}\triangle \mathrm{HAQ}-\mathrm{DI} \\
\mathrm{LS} \text { mean }(\mathrm{CI})\end{array}$ & $\begin{array}{c}-0.3^{* * *} \\
(-0.4,-0.3)\end{array}$ & $\begin{array}{c}-0.4^{* * *} \\
(-0.5,-0.3)\end{array}$ & $\begin{array}{c}-0.1 \\
(-0.1,0.1)\end{array}$ & $\begin{array}{c}-0.5 * * * \\
(-0.6,-0.5)\end{array}$ & $\begin{array}{c}-0.6^{* * *} \\
(-0.7,-0.6)\end{array}$ & $\begin{array}{c}-0.3 \\
(-0.3,-0.2)\end{array}$ \\
\hline
\end{tabular}

${ }^{*} \mathrm{p}<0.05,{ }^{* *} \mathrm{p}<0.001,{ }^{* * *} \mathrm{p}<0.0001$ vs placebo

$\mathrm{BD}$, twice daily; CDAI, clinical disease activity index; CI, 95\% confidence interval; DAS28, Disease Activity Score in 28 joints with erythrocyte sedimentation rate; HAQ-DI, Health Assessment

Questionnaire-Disability Index; LDA, low disease activity, LS, least squares; SD, standard deviation 
$\mathrm{BL}$ characteristics were balanced between treatment groups in each disease severity category. M3 efficacy was significantly greater with tofacitinib 5 and $10 \mathrm{mg}$ BID vs placebo, regardless of BL disease severity. As expected, larger proportions of tofacitinib-treated pts with moderate vs severe BL RA achieved LDA by either DAS28 $(32.3-36.7 \%$ vs $13.8-19.1 \%)$ or CDAI $(49.2-55.0 \%$ vs $26.0-31.7 \%$ ). Similarly, a higher proportion of pts achieved remission in the moderate vs severe BL groups by DAS28 $(20.0-22.8 \%$ vs $6.2-9.0 \%)$ or CDAI (11.5-12.1\% vs $5.1-6.7 \%)$. A greater proportion of pts achieved HAQ-DI $<0.5$ with moderate vs severe RA classified by BL DAS28 (45.0-60.6\% vs $24.5-30.0 \%)$ or BL CDAI (40.8-52.4\% vs $24.7-30.4 \%)$. Greater improvements from BL in disease activity and HAQ-DI were seen for pts with severe vs moderate RA classified by BL DAS28 (Table), and by BL CDAI (Tofacitinib 5/10 mg BID $\triangle$ CDAl: $-21.1 /-23.0$ vs $-8.1 /-9.4 ; \triangle \mathrm{HAQ}$ DI: $-0.5 /-0.6$ vs $-0.3 /-0.4)$.

Conclusions: Tofacitinib 5 and $10 \mathrm{mg}$ BID demonstrated efficacy in treating pts with moderate and severe RA with $>7$ years' mean disease duration. By M3, pts with severe vs moderate BL disease activity had greater improvements in disease activity and physical functioning; higher proportions of pts with moderate vs severe BL disease activity achieved remission, LDA or normal physical functioning. Interpretation of this post hoc analysis may be limited by the smaller sample size of the moderate disease group and the combining of mono- and combination-therapy results.

Acknowledgements: This study was sponsored by Pfizer Inc. Editorial support was provided by A Pedder of CMC and funded by Pfizer Inc

Disclosure of Interest: S. Schwartzman Consultant for: Pfizer Inc, P. Sunkureddi Grant/research support from: Pfizer Inc, Consultant for: Pfizer Inc, Speakers bureau: Pfizer Inc, L. Takiya Shareholder of: Pfizer Inc, Employee of: Pfizer Inc, M. Snyder Shareholder of: Pfizer Inc, Employee of: Pfizer Inc, H. Fan Shareholder of: Pfizer Inc, Employee of: Pfizer Inc, T. Lukic Shareholder of: Pfizer Inc, Employee of: Pfizer Inc, J. Roberts Shareholder of: Pfizer Inc, Employee of: Pfizer Inc, W. F. Rigby Grant/research support from: Amgen, Pfizer Inc, Roche, Consultant for: Bristol-Myers Squibb, Eli Lilly, Pfizer Inc, Roche

DOI: 10.1136/annrheumdis-2017-eular.1846

\section{AB0437 EFFICACY AND SAFETY OF LONG-TERM ANALGESIC THERAPY WITH ETORICOXIB FOR PATIENTS WITH RHEUMATIC DISEASES}

S. Lapshina, L. Myasoutova. Kazan State Medical University, Kazan, Russian Federation

Background: There are some data in literature on decompensation of arterial hypertension and other chronic diseases during the treatment with coxibs which in practice unfortunately limits their administration for patients with comorbidities. Objectives: To evaluate the efficacy of analgesic effect of etoricoxib and frequency of comorbidities exacerbation on such treatment.

Methods: 58 patients with rheumatoid arthritis $(34,4 \%)$, osteoarthritis $(29,2 \%)$, ankylosing spondylitis $(19 \%)$, gout $(14 \%)$, psoriatic arthritis $(3,4 \%)$ at the age of 25 to 75 years (the average age, $52,9 \pm 13,03$ years) were included. $79,3 \%$ patients had comorbidities (diseases of digestive system $-37,9 \%$, arterial hypertension - 53,4\% (including 3,2\% with decompensated hypertension), bronchial asthma $-1,7 \%$ ). All the patients before the appointment had taken NSAIDs (diclofenac, nimesulid, ketoprofen, meloxicam, aceclofenac, ibuprofen) with lack of effect $(84,4 \%)$ or minimal effect $(15,6 \%)$. Etoricoxib was administered in $100 \%$ cases. Pain severity according to visual analogue scale (VAS), comorbidities exacerbation and blood pressure were assessed at the beginning and during the first month of treatment.

Results: The average time period between 2 appointments was $20,72 \pm 9,3$ days. By the second appointment $98,2 \%$ patients were taking etoricoxib regularly, and good tolerability of the medication was noted $(63,8 \%$ excellent, $36,2 \%$ good). The average VAS score at the first appointment was $7,27 \pm 1,04$, at the second appointment $-2,75 \pm 1,12$, in the meantime VAS score improvement was noted mostly in the group of patients with long disease duration (more than 3 years). At the time of second examination total relief of back pain was revealed in $16,7 \%$, in knee joint $-35,5 \%$, in hip joint $-68,1 \%$, in the neck $-61,9 \%$, in small joints $30,8 \%$, of shoulder blade pain $-82,4 \%$. No comorbidities exacerbation was noted. There were also no cases of sudden blood pressure increase on the administered therapy, including patients with arterial hypertension.

Conclusions: Etoricoxib administration leads to significant decrease of pain syndrome and its relief without increasing blood pressure and exacerbations of chronic comorbidities.

Disclosure of Interest: None declared

DOI: 10.1136/annrheumdis-2017-eular.3972

\section{AB0438 RHEUMATOID ARTHRITIS DRUG THERAPY IN THE PERIOPERATIVE PERIOD OF LARGE JOINTS ARTHROPLASTY, ITS IMPACT ON THE LONG-TERM RESULTS OF SURGERY}

S. Lapshina ${ }^{1}$, I. Akhtyamov ${ }^{1,2}$, I. Gilmutdinov ${ }^{2}$, L. Myasoutova ${ }^{1} .{ }^{1}$ Kazan State Medical University; ${ }^{2}$ Republic Clinical Hospital, Kazan, Russian Federation

Objectives: To analyze the results of large joints arthroplasty depending on the received rheumatoid arthritis (RA) drug therapy

Methods: Knee and hip joints arthroplasty was performed for 54 RA patients (48 women, 6 men), mean age $51,4 \pm 12,8$ years. At the time of the operation disease duration was $11,8 \pm 3,8$ years, high activity (DAS28) - in $26 \%$, moderate - in $55.5 \%$, the low - at $18.5 \%$ patients. At the time of surgery $39(72.2 \%)$ pts continued to take basic anti-rheumatic drugs (DMARDs) (methotrexate at a dose of 10-20 $\mathrm{mg}$ per week - 32, leflunomide (20 mg daily) -5 ). Corticosteroids (prednisone at a dose of $5-15 \mathrm{mg}$, an average of $7.1 \mathrm{mg}$ per day) - 25 (46.2\%) patients, of which in combination with DMARDs - $10(18.6 \%)$. Before the operation, and after the 6 months joint pain (VAS), disease activity - DAS28, functional ability HAQ index were evaluated. In 32 patients, these same indexes were estimated after 12 months.

Results: The reduction of pain intensity VAS was observed in the first month after a joint arthroplasty, after 6 months VAS fell almost to $31.8 \mathrm{~mm}(p<0.05)$. Activity of the disease decreased (high - $11.2 \%$, moderate $-44.4 \%$, low - $44.4 \%$ ), HAQ from $1,61 \pm 0,41$ to $1,09 \pm 0,26(p<0,05)$. After 12 months HAQ $-1,01 \pm 0,28$.

The analysis showed that in patients not receiving corticosteroids $(n=29)$ arthroplasty was conducted in $13,6 \pm 3,2$ years after RA onset, and receiving long-term steroids $(n=25)$ significantly earlier $(p<0,05)$ - through $9,9 \pm 3,5$ years. The functional capacity of patients in the group receiving DMARDs without corticosteroids $(n=29)$ (the HAQ 6 months - 0,9 $\pm 0,24,12$ months - $081 \pm 0,16$ ) was significantly $(p<0.05)$ higher compared with patients receiving corticosteroids $(n=25)$ without the basic treatment (HAQ 6 months $-1.13 \pm 0.21$, over 12 months$1,24 \pm 0,19)$

Conclusions: Large joints arthroplasty is an effective method to improve the functional capacity of patients with RA. For patients receiving corticosteroids need of arthroplasty arises a few years earlier. The function of the joints after surgery and in the remote period is better when patients continuously receive DMARDs compared to steroid therapy, the dose should be reduced to a reasonable minimum for the time of surgical treatment.

Disclosure of Interest: None declared

DOI: 10.1136/annrheumdis-2017-eular.3955

\section{AB0439 EFFICACY AT THREE YEARS OF DAILY CLINICAL USE OF IGURATIMOD IN PATIENTS WITH RHEUMATOID ARTHRITIS}

T. Suto $^{1}$, Y. Yonemoto ${ }^{1}$, K. Okamura ${ }^{1}$, M. Tachibana ${ }^{1}$, C. Okura ${ }^{1}$

M. Matsushita ${ }^{2}$, K. Takeuchi ${ }^{2}$, K. Otsuka ${ }^{2}$, K. Ayabe $^{3}$, T. Kaneko $^{4}$, Y. Tamura ${ }^{4}$, M. Inoue ${ }^{5}, \mathrm{H}$. Inoue ${ }^{4}, \mathrm{H}$. Chikuda ${ }^{1}{ }^{1}$ Department of Orthopaedic Surgery, Gunma University Graduate School of Medicine, Maebashishi; ${ }^{2}$ Department of Orthopaedic Surgery, Isesaki Fukushima Hospital, Isesakishi; ${ }^{3}$ Department of Orthopaedic Surgery, Keiyu Hospital, Tatebayashishi; ${ }^{4}$ Department of Orthopaedic Surgery, Inoue Hospital; ${ }^{5}$ Department of Medicine, Inoue Hospital, Takasaki, Gunma, Japan

Background: Iguratimod (IGU) is a small-molecule antirheumatic drug that was developed in Japan and is currently only approved for treatment of rheumatoid arthritis (RA) in Japan and China. IGU suppresses tumor necrosis factor-alphainduced production of interleukin (IL)-6, IL-8 and monocyte chemoattractant protein 1 via the inhibition of nuclear factor-kappa B activation in cultured human synovial cells and human acute monocytic leukemia cells. There are some reports about the efficacy and safety of IGU in patients with RA. However, the assessment about efficacy of the clinical use of IGU has mainly been restricted to short-term (within one year) outcome.

Objectives: The purpose of this study was to assess the efficacy of IGU in 3 years

Methods: Sixty-nine RA patients (14 males and 55 females, mean age of 63.9 years, mean disease duration of 14.9 years) were enrolled in this study. The clinical course of RA was evaluated during 3 years. The patients who discontinued the IGU therapy were analyzed by the last observation carried forward method.

Results: The survival rate at 3 years was $49.3 \%$, and 8 patients discontinued the IGU therapies due to insufficient response, 12 patients due to adverse events such as exanthema, pneumonitis or hepatic disorder, and other patients based on their requests. The DAS28-CRP, DAS28-ESR, SDAI and CDAI significantly decreased at 6 months, 1, 2, 3 years compared with baseline. The low DAS28-CRP at 3 months and younger age were associated to the continuation of IGU. Furthermore, 27 patients $(39.1 \%)$ were in remission at 3 years. In the remission achievement group, the DAS28-CRP and the usage rate of prednisolone at baseline were significantly lower and patients' age was younger. A logistic regression analysis revealed the low DAS28-CRP and low usage rate of prednisolone at baseline were significant factors contributing to the achievement of a clinical remission at 3 years.

Conclusions: We assessed middle-term outcome of the clinical use of iguratimod therapy in RA patients. The low DAS28-CRP and low usage rate of prednisolone at the initiation of IGU were significant factors of clinical remission achievement at 3 years.

References:

[1] Duan XW, Zhang XL, Mao SY, Shang JJ, Shi XD. Efficacy and safety evaluation of a combination of iguratimod and methotrexate therapy for active rheumatoid arthritis patients: a randomized controlled trial. Clin Rheumatol. 2015 Sep;34(9):1513-9.

[2] Mimori T, Harigai M, Atsumi T, Fujii T, Kuwana M, Matsuno H, Momohara S, Takei S, Tamura N, Takasaki Y, Ikeuchi S, Kushimoto S, Koike T. Safety and effectiveness of 24-week treatment with iguratimod, a new oral diseasemodifying antirheumatic drug, for patients with rheumatoid arthritis: interim 